\title{
La promoción fílmica en el universo digital. Hacia el ocaso de la exhibición cinematográfica en España.
}

\author{
Luis DELTELL \\ Universidad Complutense de Madrid \\ ldeltell@ccinf.ucm.es \\ Emilio C. García Fernández \\ Universidad Complutense de Madrid \\ avia@ccinf.ucm.es
}

\section{Resumen:}

Este artículo es un resumen de una investigación sobre la situación de la promoción, distribución y exhibición cinematográfica en España. Abordamos las nuevas formas de promoción y exhibición y el nuevo modelo de espectador/audiencia en el mundo digital que nos rodea.

Palabras clave: marca; cine español; internet

Film Promotion in the Digital Universe. The End of the Cinema Exhibition in Spain.

\begin{abstract}
This article is a research on the status of the promotion, distribution and exhibition in Spain. Tackling the new forms of promotion and exhibition and the new model of viewer/spectator/audience in the Digital Universe.
\end{abstract}

Key Words : Brand; Spanish Cinema; Internet

Referencia normalizada:

Deltell, L.; García Fernández, E. C. (2013) La promoción fílmica en el universo digital. Hacia el ocaso de la exhibición cinematográfica en España. Historia y Comunicación Social. Vol. 18 № Especial Noviembre. Págs. 203-217.

Sumario 1. Introducción. 2. Metodología. 3. Sobre la idea de promoción cinematográfica. 4. La exhibición en sala o tradicional: estudio comparado España-Europa. 5. El nuevo espectador en el universo digital y la autocomunicación de masas. 6. Análisis y discusión de nuevas formas de exhibición cinematográfica. 7. Conclusiones. 8. Referencias Bibliográficas.

\section{Introducción}

En el cine español la crisis es una constante. La única característica que se mantiene en toda la filmografía de España desde el período silente hasta nuestros días es que 
siempre se ha encontrado en crisis, su única meta era y es sobrevivir. El cine español únicamente parece "preocupado por subsistir" (García Fernández, 1985: 1). Así no extraña que también en 2013, en una de los peores momentos de la economía del país, la industria fílmica se declare, una vez más, en crisis. Muchos de los actores principales del cine afirman, una vez más, que el cine español va a desaparecer en breve.

Las dificultades actuales que golpean a todos los sectores cinematográficos y a la marca cine español ${ }^{1}$ no son pequeñas: unos presupuestos mínimos (a veces completamente ridículos), una cuota de pantalla baja (según los datos del ICAA la más baja en lustros), carestía de nuevas ideas y de nuevos formatos rentables económicamente...; pero de todas ellas, hemos decido centrarnos en dos problemas: la promoción cinematográfica y la exhibición de las obras. Por tanto, del esquema tradicional de la industria cinematográfica: producción, distribución y exhibición, nos detendremos en los dos últimos pasos.

El proceso más espectacular de esta bancarrota es la clausura de las salas de cine por toda España. Así, por ejemplo, en Madrid el número de salas vacías y abandonadas (o destruidas) representa casi una cuarta parte de las que se encontraban en activo hace tan solo una década. Del mismo modo el cierre de las salas insignia demostraron hasta qué punto el espectáculo cinematográfico se encontraba herido en España. Así, el abandono de los cines Palacio de Música en Madrid, y el cine Urgel en Barcelona, el más grande y uno de los más prestigiosos durante 50 años, suponen una ruina evidente de lo que en otra época fue un entretenimiento colectivo y masivo. También resulta sorprendente a nivel europeo el desmantelamiento del grupo Alta Films en abril de 2013 (El País. 18-4-2913); o que sorprenda que el grupo Abaco Cinebox, con 19 salas y 193 pantallas, entre en liquidación en junio de 2013 (Cine\&Tele. 26-62013).

Aunque no existen datos fiables (ya que productores, exhibidores y el Ministerio de Cultura utilizan metodologías distintas y, en consecuencia, resultados y cifras distintas) se puede hablar de la pérdida de la afición al cine por parte de los españoles. Las investigaciones más detalladas, que proceden de fuentes distintas (y con intereses a veces opuestos) reflejan como el público ha abandonado el hábito de acudir a la sala de cine. En el 2009 la Entidad de Gestión de Derechos de los Productores Audiovisuales, desde ahora Egeda, publicó una investigación que reflejaba que el 73\% de los españoles acudía como mínimo cuatro veces a una sala cinematográfica en España (Egeda, 2009: 29). Aunque ya en el 2009 se percibía como un dato preocupante, los autores de las encuestan reconocían que se mantenía una tendencia positiva: "a los españoles nos encanta ir al cine" (Egeda, 2009: 28).

No obstante, en el último memorándum publicado sobre hábitos y aficiones artísticas realizada por el Ministerio de Educación, Cultura y Deporte, a partir de ahora MECD, se indica que solo el $49 \%$ de los españoles entró una vez, o más veces, en el cine durante el año 2011 (MECD, 2012). Es decir, en menos de un lustro se ha retrocedido 24 puntos porcentuales en el hábito de asistencia a la sala. 
Se trata de una recesión inmensa que cuestiona la rentabilidad económica no la producción, la promoción y la exhibición. En este artículo exponemos y presentamos las conclusiones de una investigación sobre las alternativas empresariales que la industria audiovisual ha tomado para salvar el problema. En especial, centramos nuestro objeto de estudio en dos campos: la relación de la exhibición cinematográfica tradicional en España y Europa y los nuevos modelos de exhibición.

\section{Metodología e hipótesis}

El trabajo que presentamos es fruto de una investigación multidisciplinar sobre el concepto de marca cine español en los sectores de la promoción, distribución y exhibición. Para realizar este trabajo hemos abordado, por tanto, metodología de diversas áreas y disciplinas de las ciencias sociales y del mundo del arte.

Nuestro trabajo observa los hábitos y cambios en la promoción y exhibición cinematográfica en España. Por ello se analiza el comportamiento de los espectadores (no solo en la esfera pública sino también en la esfera pública virtual) y, también, las nuevas herramientas y estrategias utilizadas por las empresas para promocionar y distribuir.

En primer lugar hemos recurrido al estudio de las investigaciones recientes sobre el mundo audiovisual en España, Europa, EE.UU y Japón. Para ello utilizamos los memoranda publicados por EGEDA, FACUA, FAPAE y el MECD, en concreto los informes del ICAA. En el entorno internacional hemos consultado los textos facilitados por el Observatorio Audiovisual Europeo (European Audiovisual Observatory).

Además nuestro trabajo tiene un soporte de metodología cuantitativa y otra cualitativa. Organizamos en dos líneas las técnicas utilizadas. Las técnicas cuantitativas se han basado en el estudio de las herramientas en red para poder estudiar el comportamiento de los usuarios de Twitter, Facebook y otras redes sociales. Especial importancia para el estudio del caudal de tweets en Twitter se ha utilizado el Factor Klout así como el sistema T-hoarder diseñado por la investigadora Mari Luz Congosto de la Universidad Carlos III.

Además hemos recurrido a una metodología cuantitativa y cualitativa para comparar las distintas plataformas en Internet para distribución y exhibición de películas y contenidos audiovisuales en España.

Los objetivos de esta investigación se centraban en cartografiar el panorama de la promoción, distribución y exhibición encontrando sus problemas, sus carencias y sus nuevas estrategias. La hipótesis inicial o de partida del trabajo es que la industria cinematográfica española se encuentra sobrepasada con la magnitud del cambio social, económico y tecnológico, no ha reaccionado todavía a la transformación que se está produciendo desde hace años a su alrededor y no ha encontrado, todavía, una solución clara al reto que se le plantea. 


\section{Sobre la idea de promoción cinematográfica}

Si tenemos en cuenta que la promoción ha de sustentarse en una serie de iniciativas que fortalezcan la existencia de una película, debemos saber que quizás una de las lagunas más evidentes en la industria cinematográfica española se encuentra en cómo venden la película. Desde el MECD, el secretario de cultura, en una de sus comparecencias en el Congreso de los Diputados, apuntaba sobre la promoción exterior del cine español que "el fomento y la promoción de nuestro cine y su industria tanto dentro como fuera de nuestra fronteras se canalizará a través de las ayudas a los festivales y mercados de cine más relevantes... y que este momento se ha visto reforzado por la firma de nuevos convenios internacionales de coproducción..." (Audiovisual 451. 15-10-2013). Quizás se insiste en esta dirección por alguno de los resultado habidos en años anteriores, como cuando se señala que "el cine español recaudó el doble en los mercados internacionales que en nacional" (Cine por la Red. 20-6-2012).

\section{La exhibición en sala o tradicional: estudio comparado España- Europa}

Como hemos detallado en la introducción y antecedentes el abandono de las salas de cine es una característica que se ha extendido en el territorio español. El hábito de acudir al cine como espectáculo sufre un retroceso imparable. Este se podría entender como una consecuencias de los nuevos modelos sociales y comunicativos como la autocomunicación de masas (Castells, 2009) o por la sustitución de lo fílmico por un consumo multipantalla en la esfera digital. De este modo, lo que ocurre en España debería ser un reflejo de un cambio de tendencia que debería acontecer en todos los países europeos. Sin embargo, este comportamiento no es internacional o, al menos, no se percibe de una forma tan dramática en los Estados Unidos y Europa, donde el hábito de acudir a la sala de cine se mantiene estable e, incluso, aumenta en algunos países.

Según los datos publicados por el Observatorio Audiovisual Europeo (European Audiovisual Observatory, a partir de ahora OBS) el descenso de público entre la temporada de 2010 y la de 2011 fue solo de $-0,57 \%$ en la media del continente mientras en España alcanzó $-7,1 \%$. Hubo naciones como Francia, Suecia y Alemania que experimentaron aumentos entre el 3\% y el 5\% e incluso los países bálticos (Lituania y Estonia) y Rumania incrementaron el número de espectadores en más de un $10 \%$. Algo parecido sucede en los EE.UU., Canadá y Japón donde las cifras parecen mantenerse estables. Por todo ello, el abandono, casi huida, de las salas de cine que sufre España no ocurre en el panorama internacional, sino que es, sobre todo, un hábito y una peculiaridad nacional.

No obstante, la Comisión Europea, en los primeros meses de 2012, puso en marcha una iniciativa de distribución, conocida como "Circulación de las películas en la era digital" - de la que no se conocen resultados-, con la que se pretendía evaluar en qué medida se beneficiarían las películas al ser estrenadas simultáneamente en diferentes 
plataformas en el mismo día. O lo que es lo mismo: sustituir el lanzamiento tradicional por ventanas por el estreno en sala de cine, televisión, VOD e Internet. Algunos productores consideraron que este tipo de lanzamiento animaría al espectador a ver la película que se estrenara. Quizá la iniciativa buscaba equilibrar las situaciones que se estaban produciendo con el estreno de determinadas películas (cine de autor) y del mercado en ciertos países (Cine por la Red. 26-10-2012). Las grandes organizaciones de exhibidores europeos no tardaron mucho tiempo en criticar dicha iniciativa con la que, según sus palabras, "amenazan el futuro de la industria cinematográfica europea"; o más concretamente, supone una "amenaza para el futuro de la exhibición cinematográfica y la capacidad de los Estados miembros para decidir la mejor forma de apoyar al cine y a los cines en sus respectivos territorios" (Cine por la Red. 11-122012).

En cualquier caso, los datos españoles de 2013 no se esperan mejores. Pedro Pérez, pocos meses antes de dimitir como Presidente de la FAPAE, declaraba que "se encontraban en estado de pánico". El número de espectadores había descendido un " $30 \%$ respecto a la peor temporada registrada" (El País, Álvaro P. Ruiz, 18-6-2013).

Como dijimos en la introducción, la evidencia más palpable de este abandono del espectáculo cinematográfico son los continuos cierres de las grandes salas en el centro de todas las ciudades y capitales. Esta práctica que comenzó en el período finisecular del siglo XX y se aceleró en el presente, ha llevado a que lugares míticos de la historia del cine español se encuentren abandonados. La Gran Vía madrileña celebró su centenario con menos de cinco cines en activo y con varias de las viejas salas abandonadas y en estado de ruina. De manera aún más dramática, la mitad de las capitales de provincia del Estado no tienen una sala de cine en el centro urbano.

Esta tendencia de cierre de salas parecía compensarse con el crecimiento en el número de pantallas. Así, mientras se cerraban los grandes y pequeños cines con una única pantalla se abrían complejos multisalas con varias pantallas (algunos con más de 20). No obstante, esta estrategia, también, ha fallado y en la última década se ha perdido más de 600 pantallas y 400 cines (los datos de 2013 aún son provisionales).

Tabla 1. Evolución del número de salas y pantallas en España.

\begin{tabular}{|l|c|c|c|c|c|c|c|c|}
\hline Año & $\mathbf{2 0 0 3}$ & $\mathbf{2 0 0 4}$ & $\mathbf{2 0 0 5}$ & $\ldots$ & $\mathbf{2 0 1 0}$ & $\mathbf{2 0 1 1}$ & $\mathbf{2 0 1 2}$ & $\mathbf{2 0 1 3}$ \\
\hline Pantallas & 4.253 & 4.390 & 4.401 & $\ldots$ & 4.080 & 4.044 & 4.003 & 3.600 \\
\hline Salas de cine & 1.194 & 1.126 & 1.052 & $\ldots$ & 860 & 876 & 841 & 790 \\
\hline
\end{tabular}

Fuente: ICAA. Elaboración propia

El hábito de acudir a la sala de cine, como espectáculo público, parece definitivamente sentenciado en España. Gracia Querejeta, el día en que su película 15 años y un día fue elegida para representar a España en los Oscar, señaló que "Quizá al cine en pantalla le queden los días contados, pero al audiovisual, no" (20minutos. 14-10-2013). Sin duda, este se debe a muchos factores, algunos tecnológicos como veremos en el capítulo a continuación, pero otros a cuestiones económicas que no se 
han tenido en cuenta con frecuencia. La subida del IVA a un $21 \%$ parece, y es, uno de los problemas fundamentales de este abandono de la sala de cine ("La industria del cine español, en coma”. El País, 27-9-2013).

Sin duda el precio de una entrada de cine en España es elevado, elevadísimo si nos atenemos a los estudios de la FACUA. Así en el período de 2005-2012 (antes de la subida del IVA) el precio de la entrada de cine se había incrementado en un $36 \%$ (informe FACUA) siendo uno de los productos que más había aumentado en su precio en todo el mercado español. Además al comparar el precio de la entrada en España con el de Europa encontramos que el nacional es mucho mayor en la relación precio / ingreso. Aún más como denunciaba FACUA, los cines españoles recurrían a ciertas prácticas fraudulentas de los exhibidores. El aumento del precio en las entradas no se acompañó con ayudas, bonos o carnet, como sí ocurrió en Francia, Alemania... países que han experimentado un aumento en el número de espectadores en sus salas. En la recta final de 2013, algunos gobiernos europeos están dispuestos a revisar a la baja el IVA que se contempla en la entrada del cine; Francia quiere pasar del 7\% actual al 5\% (El País, 27-9-2013).

\section{El nuevo espectador en el universo digital y la autocomunicación de masas}

Sin lugar a dudas, el abandono de las salas de cine en España, es un proceso sin cambio de sentido. Pero, llama poderosamente la atención el esfuerzo y la inversión que los sectores de distribución y exhibición están haciendo para implantar la digitalización en el negocio, conociendo como se ha establecido una gran competencia entre la pantalla tradicional y las otras plataformas. Sin duda es un reto el plantearse como volver a repescar a todos los espectadores que han abandonado la sala de cine. El horizonte no se presenta despejado, porque los contenidos alternativos que surgen en otras plataformas llegan con gran fuerza en el conjunto de oferta audiovisual, lo que se convierte, a su vez, en fuente de ingresos para muchos nuevos operadores (Cineinforme. Julio-Agosto 2013)

Ya en 2005 se presentó un estudio sobre el comportamiento de los adolescentes con relación a la televisión y al cine que reflejaba un desapego al modelo tradicional. Los jóvenes madrileños se presentaban en nuestro estudio como "huérfanos y náufragos" en los hábitos de consumo audiovisual (Deltell, 2005). En esta investigación se descubría que los adolescentes consumían televisión, cine y cualquier relato audiovisual por medio de Internet. Este proceso se ha acelerado de forma significativa en los últimos años. Lo sorprendente no ha sido que los nativos digitales se ubicasen en la Red, sino, sobre todo, que la sociedad en su conjunto ha comenzado a tener un comportamiento plenamente digital. En España, el consumo audiovisual de los migrantes digitales es, cada día más y más, similar al de los nativos según el último informe del MECD (MECD, 2013).

El abandono de las salas de cine no supone en ningún caso la ausencia de consumo audiovisual. Algunos informes, como el de EGEDA, indican que el número de horas 
dedicadas a la televisión por hogar se mantiene estable. Y, aún más, si se tiene en cuenta el uso de productos audiovisuales en otros soportes, el consumo audiovisual global ha aumentado. Lo que se ha modificado es el sistema y el lugar de uso. La ubicación es ahora por Internet. Manuel Castells, tal vez un ciberoptimista, sostiene que el espectador actual es, gracias a las redes sociales y a la tecnología, una "audiencia creativa" (Castells, 2009). Una audiencia que participa y opina de forma activa en las redes sociales.

Este nuevo modelo, también defendido por Peter Dahlgren (Dahlgren, 2009), se plantea un nuevo paradigma social, comunicativo y político. Aunque estos autores no abordan el consumo de "cine", lo cierto es que las implicaciones de sus teorías evidencian, de forma indirecta, los nuevos usos y hábitos del público ante el cine. La base central de este nuevo paradigma es que el espectador se convierte de manera directa en emisor. Esto surge gracias a las redes sociales en internet. La audiencia de contenidos audiovisuales deja de ser un espectador/receptor pasivo para ser un creador potencial. Esta tendencia condiciona lógicamente el consumo del cine. Mientras que en el sistema tradicional el público se entendía como un receptor "pasivo" que contempla un simulacro de la realidad, "el registro de la vida en si" (Stam, 2001: 37), en los nuevos medios el espectador es una audiencia "activa" (Castells, 2009: 174).

La "actividad" del espectador creativo viene dada por su participación y elaboración de debates en torno a películas, en la elaboración de vídeos (parodias para colgar en YouTube, falsos avances...), comentarios en páginas webs (Imbd.com, Filmaffinity...) y productos derivados (fakes) en Facebook u otras redes sociales. Sin duda, uno de los ámbitos predilectos para la creación de opinión sobre cine y películas es Twitter. Este espacio de microblogging se ha transformado en un auténtico medidor social.

La nueva audiencia (o audiencia creativa) tiene como primer característica su actividad, su capacidad de transformarse en emisor. Pero la segunda singularidad, tan importante como la primera, y que pasa desapercibida con frecuencia, es que se trata de un consumo individual y sin espacio físico. Es decir, el espectador audiovisual actual representa un cambio radical, ya no debe acudir a un espacio (sala de cine) y sumarse a una colectividad anónima y desconocida para contemplar una obra, sino que lo hace de una forma individual, sin espacio físico necesario (ya que se trata de virtual) y, se espera de él, una respuesta activa.

Tabla 2. Espectador tradicional versus espectador creativo.

\begin{tabular}{|l|l|l|}
\hline & Espectador tradicional & Espectador creativo \\
\hline Espacio de consumo & Sala de cine & Ordenador, Móvil, Tablet, otras pantallas... \\
\hline Evento & Acto social comunitario & Acto privado o doméstico \\
\hline Tecnología & Proyección en celuloide & $\begin{array}{l}\text { Contenidos digitales (proyección digital, } \\
\text { Internet) }\end{array}$ \\
\hline Actividad & Pasivo - Receptor & Activo Receptor-reemisor \\
\hline
\end{tabular}

Fuente: varia. Elaboración propia 
El abandono de las salas de cine que acontece en España se debe a un cambio de paradigma. Es cierto, como hemos visto, que este no se ha dado en toda Europa, pero sí se percibe y, como indica Lec Manovich, las tendencias digitales mostradas por líderes terminan por "manifestarse" en el conjunto de la sociedad (Manovich, 2005: 72). Es cierto que el entusiasmo por las nuevas tecnologías, y muy especialmente por las posibilidades de las redes sociales para crear un espectador creativo, encuentran fuertes retractores. Morozov ha demostrado como el "optimismo" de los grandes defensores de la Red está injustificado y que, en muchos casos, Internet no contribuye a crear un público y sociedad mas activa, sino más pasiva y dominada (Morozov, 2009)

\section{Análisis y discusión de nuevas formas de exhibición cinematográfica}

La "audiencia creativa" ha transformado el espectáculo audiovisual en algo privado (y casi solitario) y de carácter doméstico. Los grandes cines y, también, los complejos multisalas carecen de utilidad, ya que ahora el consumo de productos fílmicos y audiovisuales se trata de una diversión no pública. Este fenómeno es internacional y, por ello, todos los países han ideado soluciones al mismo. Si el nuevo espectador/ audiencia prefiere contemplar las películas en su hogar es necesario ofrecerles un canal de exhibición directo: las plataformas en red cuyo modelo más popular internacionalmente es Netflix.

La investigadora Jessica Izquierdo Castillo ha estudiado las diferentes plataformas en red que existen en el mercado. Se presentan tres modelos básicos en la construcción de estas aplicaciones: "el micropago, la cuota mensual y el pago por publicidad (Izquierdo-Castilla, 2012: 388). Estos sistemas han tenido éxitos diversos en su implantación. Sin duda, el modelo más consolidado es el ya citado de Netflix, plataforma de contenidos audiovisuales que opera principalmente en EE.UU. y que bajo una cuota mensual (entorno a los 15 dólares) permite al usuario estadounidense ver en streaming (sin descarga) películas, series y otras producciones.

En España la siguiente gran plataforma de contenidos digitales (aunque no audiovisuales sino musicales) es Spotify. Dicha compañía de origen sueco permite a sus clientes dos modalidades de consumo: gratuita (pero con publicidad y con restricciones) o de pago mensual (con distintas categorías). Pero, los resultados de Spotify son ruinosos. Aún menos exitosa resulta la plataforma de contenidos creada por EGEDA: Filmotech, que permite al usuario alquilar y ver en streaming producciones cinematográficas, casi la totalidad son españolas y co-producciones. Su funcionamiento es deficiente y un gran número de clientes se ha quejado de los fallos y caídas del sistema. Junto a Filmotech existen otras dos plataformas importantes como Filmin y Youzee. Sin embargo, ninguna de ellas ha logrado posicionarse en el mercado.

Son los dispositivos a-legales los que se han consolidado. La piratería digital es uno de los temas más controvertidos en la sociedad española. Aunque los motivos de esta actitud sociológica sobrepasan a esta investigación, sus consecuencias son 
directas en la industria cinematográfica nacional. España es el único país europeo que ha sido incluido repetidamente en el catálogo de los EE.UU. como Estados "piratas". La Ley para una Economía Sostenible (popularmente conocida Ley Sinde) reflejó la división de la sociedad española en este tema. Al proyecto de la ministra González Sinde se sumaron los creadores y las sociedades de derechos de autores (especialmente SGAE); frente a ellos se situó un gran porcentaje de la sociedad española cuya cabeza más visible fueron los movimientos piratas y colectivos como Anonymous.

En 2013 el Observatorio de Piratería y Hábitos de Consumo de Contenidos Digitales (a partir de ahora OPHCD), ente financiado por los creadores, productores y el MECD, publicó las cifras que presuponemos más exactas. Su estudio se basaba en encuestas realizadas a internautas de 11 A 74 años (es decir tanto nativos digitales como usuarios adultos). La cifra ofrecida respecto el cine resultaba esclarecedora: el $43 \%$ de los estudiados reconocía haber adquirido de forma ilegal películas. Este dato es muy superior a los que pirateaban música (32\%) o libros (tan solo el $12 \%$ ).

El estudio de OPHCD no nos permite saber de qué países son esas películas (tal vez el impacto en el cine español sea menor o mayor), pero debemos suponer que el alcance debería ser similar a la cuota de pantalla del cine español en la cartelera tradicional. Creemos que un buen cálculo para ponderar el efecto sería establecer como medida la cifra de cuota de pantalla. Es decir, si un $43 \%$ de los usuarios se descargan películas, alrededor del 7\% copiarían películas españolas.

El trabajo del OPHCD si nos ofrece una información significativa: la percepción del acto. El 69\% de los internautas que descargar ilegalmente producciones audiovisuales consideran que "no deben pagar por contenidos que pueden conseguir gratis" y un $25 \%$ incluso reconocen que para ellos se trata de un "derecho del internauta" y no es en absoluto un delito (OPHCD, 2013).

La legalidad o ilegalidad del acto de la piratería es un tema que sobrepasa completamente los objetivos propuestos en nuestra investigación. Sin embargo sus consecuencias son palpables en el cine. Según los datos de OPHCD el 69\% de los internautas españoles no pagarían por ver cine o productos audiovisuales y el mercado, lógicamente, solo se reduce a un exiguo $31 \%$ de la población lo cual hace inviable una industria tan costosa como la cinematográfica. La percepción de la piratería y el comportamiento de los usuarios harían insostenible cualquier sistema de distribución online, que no fuese prácticamente gratuito.

Para terminar este punto, debemos señalar que por encima de cualquier modelo de exhibición online nos encontramos con un sector -la distribución- que participa activamente en el desarrollo del modelo pero que, según los últimos datos publicados, no está preparado para el usuario digital. En el estudio "La identidad digital de distribuidoras y exhibidores", realizado por Estudios de Internet, se indica que, analizadas 34 distribuidoras de forma individual, se confirma la situación de "que el 94,11\% de las distribuidoras no disponen de Web accesible para smartphones ó el 85,3\% no disponen de e-commerce en su Web, en un país en el que el 66\% de la población dispone de smartphones y más de la mitad de ellos han comprado con sus terminales". Sabiendo 
que se consumen más contenidos audiovisuales, las distribuidoras y las plataformas que ofrecen dichos contenidos tienen que adaptar sus servicios a las necesidades del consumidor. Los mismos distribuidores reconocen que "nos estamos equivocando en el producto porque el producto que ofrecemos no es atractivo" (Cine\&Tele. 19-62013).

\section{Conclusiones}

Este artículo presenta algunas las conclusiones de una investigación sobre el concepto imagen de marca del cine español en el que abordamos los retos y dificultades en los que se encuentran la promoción, distribución y exhibición cinematográficas en España. Nuestro trabajo ha presentado como el cierre masivo de las salas de cine en el país, muy especialmente, en este año 2013, es una tendencia propia de la industria española. Si bien en el resto de Europa, de media, ha descendido un 0,57\% la asistencia al cine en España las cifras son alarmantes.

En el Estado español se observa, mejor que el resto del continente, un cambio en el perfil del espectador tradicional. Una importante parte del público, se comporta ya con "espectador creativo". Tanto nativos como migrantes digitales utilizan las plataformas en red, principalmente las a-legales, para la descarga de películas. Casi la mitad de los internautas españoles reconocen haber copiado contenidos audiovisuales, de manera a-legal o, a veces, ilegal.

Así estos "espectadores creativos" usan Internet y, en especial, las redes sociales para comentar, generar y distribuir opinión sobre las películas y otras producciones audiovisuales. Esto implica que el público abandona el papel de receptores pasivos para convertirse en autores y parte fundamental del debate.

Como se observa en el trabajo las productoras y distribuidoras españolas han planteado dos líneas o estrategias diversas para encauzar la nueva exhibición: primero, han apostado por la creación de plataformas digitales, legales y de pago; y, segundo, han realizado nuevos cambios basados en las redes sociales y en Twitter. La estrategia de las plataformas legales no ha logrado, tal vez por falta de tiempo, sus objetivos. La mayoría de las empresas creadas para estos fines son deficitarias y carecen del apoyo de los espectadores e internautas.

Hemos querido realizar una cartografía de la situación actual de la promoción y exhibición en España, mostrando que los retos (desaparición de las salas de cine y el nuevo espectador creativo) y los obstáculos (piratería y desubicación del espectáculo filmico) suponen una de las dificultades mayores por la cuales ha atravesado la industria cinematográfica. 


\section{Refencias bibliográficas}

CASTELLS, Manuel (2009). Comunicación y poder. Madrid: Alianza Editorial. CONGOSTO, Mari Luz, DELTELL, Luis, CLAES, Florencia \& OSTESO, José Miguel (2013): "Análisis de la audiencia social por medio de Twitter. Caso de estudio. Los premios Goya 2013". En ICONO 14. Junio, v. 11. N 12. p. 52-80.

DAHLGREEN, Peter (2009). Media and Political Engagemente. Nueva York: Cambrigde University Press.

DELTELL, Luis (2005): "El telespectador adolescente como náufrago". En Comunicar. Revista científica iberoamericana de comunicación y educación. Diciembre. N. 25. p. 340-355.

DELTELL, Luis, CLAES, Florencia \& OSTESO, José Miguel (2013). “Audiencias televisivas y líderes de opinión en Twitter. Caso de estudio: El Barco". En Estudios sobre el Mensaje Periodístico. Junio, v. 19. n.1. p. 347-364.

DELTELL, Luis, CLAES, Florencia \& OSTESO, José Miguel (2013). “Twitter en las campañas comunicativas de películas cinematográficas". En El Profesional de la Información. Marzo-abril, v. 22, n.2. p. 128-134.

EGEDA (2009). La percepción del cine español por el público. Madrid: Egeda. Aisge Fundación.

GARCÍA FERNÁNDEZ, Emilio C. (1985). Historia ilustrada del cine español. Madrid: Planeta.

IZQUIERDO-CASTILLA, Jessica (2012). "Distribución online de contenidos audiovisuales: análisis de 3 modelos de negocio", en El Profesional de la Información. Julio-agosto, v. 21. n. 4. p. 385-390.

MANOVICH, Lev (2005). El lenguaje de los nuevos medios de la comunicación. La imagen en la Era Digital. Barcelona: Paidós Comunicación.

MARWICK, Alice \& BOYD, Danah (2011). "To See and Be Seen: Celebrity Practice on Twitter”. En Convergence, 17(2), pp. 139-158. DOI: 10.1177/1354856510394539. p. 139-157.

MOROZOV, Eugeny (2009). The Dark Side of Internet Freedom. The Net Delusion. Nueva York: Public Affairs.

SERRANO-PUCHE, J. (2012). "Herramientas Web para la medición de la influencia digital: Análisis de Klout y PeerIndex". El profesional de la información, 2012, mayo-junio, v. 21, n. 3, pp. 298-303.

STAM, Robert (2001). Teoría del cine. Una introducción. Barcelona: Paidós Comunicación.

ZHANG, W. \& SKIENA, S (2009). "Improving Movie Gross Prediction Through News Analysis". En IEEE/WIC/ACM, Volume 01, pp. 301-304. DOI: 10.1109/ WI-IAT.2009.53. p. 301-304.

Informes, leyes citadas y hemeroteca

ESTUDIOS DE INTERNET (2013). Estudio sobre identidad digital en el sector del cine. http://www.estudiosinternet.com/ [21-10-2013]. 
FACUA (2004). Informe para la reforma de los medios de comunicación de titularidad del estado.http: //www.facua.org/facuainforma/2005/comitedeexpertos.pdf. [17-10-2013].

FACUA (2009). Precio entradas de cine en España. Madrid. http://www.facua.org/es/ tablas/cines2009.pdf [7-09-2013].

FACUA (2012). Hábitos audiovisuales. [17-10-2013].

MECD (2012). Encuesta de hábitos y prácticas culturales en España. 2010-2011. www.mcu.es/estadisticas/MC/EHC/2010/Presentacion.html:' [7-09-2013].

OBS (2012). www.obs.coe.int. [17-09-2013].

OPHCD (2013). Observatorio de la Piratería Digital España. www.mcu.es/libro/img/ MC/Observatorio_Pirateria2012.pdf. [23-09-2014].

Ley para una Economía Sostenible. http://www.boe.es/boe/dias/2011/03/05/pdfs/ BOE-A-2011-4117.pdf. [17-10-2013].

Audiovisual 451. 15-10-2013. [15-10-2013].

Cineinforme. Julio-Agosto 2013. [16-10-2013].

Cine por la Red. 20-6-2012. [21-10-2013].

Cine\&Tele. 19-6-2013; 26-6-2013. [22-10-2013].

El País. 18-4-2013; 18-6-2013. [17-10-2013].

Tercer Mercado. 9-7-2013. [22-10-2013].

20 Minutos. 14/10/2013. [21-10-2013].

\section{Notas}

1 Este estudio se ha realizado en el ámbito del Proyecto de Investigación I+D+i "La imagen de marca del cine español” (CSO2011-24622), financiado por el Ministerio de Ciencia e Innovación.

\section{Los autores}

Luis Deltell. Es Profesor Contratado Doctor Complutense de Madrid. Obtuvo su doctorado en Comunicación Audiovisual, Universidad Complutense de Madrid y logró el Premio Extraordinario de Licenciatura. Madrid, 2001. Además es Premio Joven de Investigación y Comunicación, Fundación General de la Universidad Complutense. Madrid, 2003.

Fue investigador en la Fundación Residencia de Estudiantes-CSIC (Centro Superior de Investigaciones Científico - Ayuntamiento de Madrid) y obtuvo la Beca de Investigación Predoctoral de la Fundación del Instituto de Crédito Oficial-Ministerio de Economía y Hacienda de España, para el estudio del Arte Contemporáneo. Madrid, 2003-2005. Disfrutó de la Beca Postdoctoral del Ministerio de Asuntos Exteriores de España en la Real Academia Española en Roma como guionista de cine en el año 
2005. Ha sido visiting scholar en Stanford University (EEUU) en el 2006. Además ha obtenido la Beca para Profesores e Investigadores de la Fundación del Amo para acudir seis meses a Stanford University en el curso 2009-2010.

Desde el 2007 trabaja en el uso del audiovisual español (cine, series televisión, textos audiovisuales y video-arte) para la transmisión de la cultura y lengua españolas. Estos trabajos se han desarrollado en diversas universidades españolas, norteamericanas y europeas. Y ha publicado artículos de investigación son el tema, además del Porfolio de Historia de España, 2012.

Ha publicado el libro Madrid en el cine de la década de los cincuenta. Área de Gobierno de las Artes (Ayuntamiento de Madrid). Madrid. 2006. Así como artículos de investigación en revistas científicas españolas e internacionales sobre cine español y estudios culturales relacionados con el arte español.

Ha sido director, videoartista y guionista de los siguientes trabajos audiovisuales: Corre, Adrián, País soñado. Di Algo, En la ciudad perdida. Con los que ha obtenido una treintena de premios internacionales y nacionales. Es fundador de la productora cinematográfica: Producciones Gozne. Además ha recibido ayudas y menciones del Ministerio de Cultura, Consejería de Cultura de la Comunidad de Madrid, Xunta de Galicia y Junta de Andalucía. En la actualidad prepara junto al investigador en estética Jordi Massó un estudio monográfico sobre el videoarte en España.

Colabora en la acción integrada del AECID. Ha sido responsable del proyecto de innovación docente de la Universidad Complutense de Madrid 2007-2008: Virtualización, metodología y prácticas de la Historia del Cine. Y en el proyecto de innovación docente de la UCM 2009-2010: Nuevas tecnologías y su uso en el aprendizaje del Español.

Como docente ha obtenido seis menciones de calidad de la Universidad Complutense de Madrid en el programa Docentia. Ha realizado estancias e intercambios de profesorado con las universidades de Bergamo, Sapienza, Sorbonne, Florenica y El Cairo.

Sus líneas de investigación actuales se encuentran entre el cine español y la literatura (prepara un monográfico sobre Antonio Buero Vallejo y el cine) y las redes sociales y la Democracia civil. Junto a profesores e investigadores de diversas universidades europeas y africanas prepara un estudio sobre el uso de Twitter como herramienta política y democratizadora.

Es miembro del Grupo Complutense de Estudios Cinematográficos (ESCINE) y forma parte del equipo de trabajo del Proyecto de Investigación I+D+i "La imagen de marca del cine español" (CSO2011-24622), financiado por el Ministerio de Ciencia e Innovación, dirigido por el catedrático Emilio C. García Fernández. 
Emilio C. García Fernández. Catedrático de Comunicación audiovisual y Publicidad en la Facultad de Ciencias de la Información de la Universidad Complutense de Madrid. Doctor en Ciencias de la Información. Sección de Imagen. Universidad Complutense de Madrid y Licenciado en Publicidad. Universidad Autónoma de Barcelona.

Su actividad docente se ha centrado en el mundo de la historia y el análisis del cine, la cultura de la imagen y de los medios de comunicación.

Desde 1996 hasta la fecha ha dirigido más de 25 tesis doctorales sobre diversos temas audiovisuales, así como más de 35 Trabajos de Investigación de Doctorado sobre diversos temas audiovisuales; además ha participado en numerosos tribunales académicos de valoración.

A lo largo de más de treinta años ha desempeñado numerosos cargos académicos e institucionales.

Tiene concedidos dos sexenios de investigación por la Comisión Nacional Evaluadora de la Actividad Investigadora.

Es miembro evaluador de diversas comisiones en agencias nacionales y autonómicas.

Ha formado parte del equipo del Proyecto Media (2002-2004), del Grupo Fonta, así como en otros proyectos de Innovación y Mejora de la Calidad Docente. Es el Director del Grupo Complutense de Estudios Cinematográficos (ESCINE. GR42710), así como Investigador Principal del Proyecto I+D+i del Ministerio de Ciencia e Innovación que lleva por título La imagen de marca del Cine Español (CSO2011-24622).

Entre sus numerosas publicaciones destacan, tanto individual como colectivamente: Historia del cine en Galicia (1896-1984). 1985; Historia ilustrada del Cine Español. 1985; Historia do cine en Galicia. 1996; Cine e Historia. Imágenes de la historia reciente. 1998; Diccionario del cine español. 1998; Memoria viva del cine español. 1998; El cine español entre 1896 y 1939. Historia, industria, filmografía y documentos. 2002; Guía histórica del cine. 1896-2001. 1996 y 2002; Diccionario do cine en Galicia. 1896-2000. 2002; Once miradas sobre la crisis y el cine español. 2003; La cultura de la imagen. 2006; El productor y la producción en la industria cinematográfica. 2009; Historia del cine. 2011; o Desmontando a Saura. 2013. Ha colaborado con EGEDA en varios Panorama audiovisual. (2006-2010).

Desde 1980 ha colaborado en numerosas publicaciones especializadas así como en prensa diaria.

Desde 1981 ha impartido numerosas conferencias y participado en otras tantas mesas redondas y presentaciones culturales en ámbitos universitarios, científicos y sociales. Desde 1987 ha presentado numerosas comunicaciones y ponencias en Congresos nacionales e internacionales.

Además del Premio Extraordinario de Doctorado (1982-83), ha recibido el Premio 'Hogar de Avila en Madrid' al Mejor Libro sobre la provincia (1988), el Premio 
"Film-Historia" 2002, a la Mejor Investigación del año, por el libro El cine español entre 1896 y 1936, concedido por el Centre d'Investigacions Film-Història del Departament d'Història Contemporània de la Universidad de Barcelona, y la Medalla del Círculo de Escritores Cinematográficos 2010 a la mejor Labor literaria y Periodística, en reconocimiento a toda una trayectoria docente e investigadora en el campo del cine.

En su actividad profesional ha sido realizador de televisión el Centro Territorial de TVE en Santiago de Compostela (Verano 1980), documentalista en la serie para TVE 'El Arte del Vídeo' (1989), Director-Realizador de: Historia de la Biblioteca de la Universidad Complutense. Producción de la Biblioteca de la Universidad Complutense (Mayo de 2005); y Los servicios de la Biblioteca de la Universidad Complutense. Producción de la Biblioteca de la Universidad Complutense (Junio de 2006).

Desde 1981 ha sido director, codirector, coordinador, promotor de todo tipo de actividades cinematográficas, destacando los 20 años de preestrenos cinematográficos realizados en la Facultad de Ciencias de la Información, el cargo de Comisario Científico de la Exposición "Historia del Cine Español", organizada por el Consorcio Madrid Capital Europea de la Cultura. Centro Conde Duque (Madrid. Mayo-Junio 1992).

Además ha sido Asesor de numerosos festivales cinematográficos de carácter nacional e internacional, así como miembro del Jurado de diversos festivales.

También es miembro de diversos Comités Científicos de Asociaciones y Revistas. 